\section{Grotesque image can never be forgotten nor forgiven}

\author{
An adult male was admitted in Rani \\ Laxmibai Medical College, Jhansi, MP, \\ India, where his leg was amputated.
}

Regrettably, the patient's amputated leg was tucked under his head as a pillow while the patient was recuperating in the emergency section of the hospital.

This situation is clearly professionally unethical, promotes medical ostracization, creates psychological issues for the victim, and works against inherent humanistic values and medical progress and accepted norms of decency. This form of mental torture may not exactly conform to the definition of torture in the Convention against Torture. However, it must certainly be degrading treatment, at the very least, and such practices must surely be condemned by the medical professional worldwide. In this case, a non-implantable body part which has become 'non-self' being used as a pillow is highly likely to seriously detrimentally psychologically affect the patient.

Why did this happen? Whilst in a hospital such incidents should never take place, still they do. The problem of lack of resources and the increase in patient load has created an atmosphere where apparently minor lapses and unethical practices are often overlooked, or normalised. Additionally, patients find it hard to question the quality of health care as their treatment is going on, particularly as they may not consider healthcare to be their birth right - despite assurances given by the Indian government. Justification for incidents such as these is often inadequacies in the health care system. However, it is our firm view that this context does not and must not give free reign for medical professionals and other to indulge in blatantly unethical and unprofessional practice. It is important that standards are maintained to avoid traumatising or tortuous environments in healthcare settings (Centre for Human Rights and Humanitarian Law Anti-Torture Initiative, 2013).

We feel obliged to speak out particularly as this is not the first time that such a practice has been identified. On this occasion, the matter was highlighted by the press (Hindi Daily, 2018). Previously, similar situations have been shown to occur time and again in India (Husain, M., Anjum, A, Alshraim, M, Usmani, A, Usmani, J.A., 2012).

We urge that such practices be stopped and counselling should be provided to those hospital employees who are so susceptible to stress that they take short cuts without realising that these may cause deep hurt and downgrade professional values.

\section{Md Mojahid Anwar, MD, Ass Prof., Mohd Asrarul Haque, MD, Ass Prof, Afzal Haroon, MD, Ass Prof., Hena Fatima, ${ }^{\star}$, Munawwar Husain, MD, Prof., **}

\section{References}

Centre for Human Rights and Humanitarian Law Anti-Torture Initiative. (2013) Torture in Healthcare Settings: Reflections on the Special Rapporteur on Torture's 2013 Thematic Report. Washington College of Law: Washington, USA.

Edward (2005). Principia Ethica. Bames \& Noble Publishing House.

Hindi Daily. (2018). Dainik Fagran, Aligarh, $11^{\text {th }}$ March 2018, p.16.

Husain (2001). A proposal to revisit the UN torture definition. Torture, 11 (21-22).

Husain, Anjum, Alshraim, Usmani, Usmani (2012). Situation Ethics: How relevant is 'right' versus 'useful' theory in ethical practice? $\mathcal{F}$ Indian Academy Forensic Med, 34 (2), pp 154-155.

UN Convention against Torture and Other Cruel, Inhuman or Degrading Treatment or Punishment. A/RES/39/46. 